Aisyah Journal of Informatics and Electrical Engineering

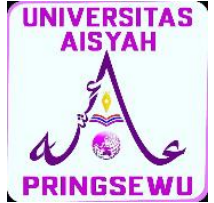
Universitas Aisyah Pringsewu

Journal Homepage

http://jti.aisyahuniversity.ac.id/index.php/AJIEE

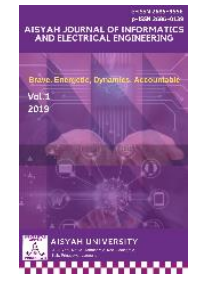

\title{
MONITORING STOK BARANG MENGGUNAKAN TEKNOLOGI PUSH NOTIFIKASI ANDROID
}

\author{
Akmal Nasution ${ }^{1}$, Iqbal Kamil Siregar ${ }^{2}$ \\ ${ }^{1}$ Sistem Informasi, Sekolah Tinggi Manajemen Informatika dan Komputer Royal Kisaran \\ ${ }^{2}$ Sistem Komputer, Sekolah Tinggi Manajemen Informatika dan Komputer Royal Kisaran \\ email: ${ }^{1}$ nst.akmal@gmail.com, ${ }^{2}$ iqbalkamilsiregar@royal.ac.id
}

\begin{abstract}
ABSTRAK
Perkembangan teknologi yang pesat mulai mempengaruhi kebiasaan para pelaku bisnis, baik itu produsen maupun distributor. Bagi produsen informasi stok barang mentah menjadi hal

yang sangat penting, karena dapat berpengaruh terhadap kelangsungan produksi. Produsen mebel misalnya, saat barang mentah seperti kayu habis atau out of stocks menyebabkan terhentinya proses produksi, sehingga berimbas ke hasil penjualan barang yang akan berkurang. Hal ini lah yang dialami oleh PT Mebel Kisaran. Meskipun sudah dipantau dengan baik, namun dalam satu tahun perusahaan tersebut rata-rata mengalami out of stock terhadap barang mentah sebanyak 9 kali. Saat menghadapi masalah tersebut rata-rata proses produksi harus terhenti selama 2 hari sampai barang mentah yang dibutuhkan tersedia kembali. Jadi dapat diambil kesimpulan bahwa dalam 1 tahun perusahaan rata-rata akan menghentikan produksinya selama 18 hari diluar jadwal kerja yang seharusnya. Hal ini tentunya akan mempengaruhi produktivitas dan penghasilan perusahaan. Untuk mengatasi hal tersebut pimpinan perusahaan melakukan investasi IT dengan pembuatan aplikasi yang mampu memonitoring dan memberikan informasi secara realtime mengenai stok barang mentah jika sudah menipis, tentunya dengan memnfaatkan teknologi push notifikasi. Untuk itu, diperlukan sebuah aplikasi mobile untuk digunakan sebagai media penyampaian informasi tersebut. Sebagai contoh dapat memberikan notifikasi jika ada stok barang mentah yang menipis, sehingga dapat diambil tindakan antisipasi sebelum barang tersebut benarbenar habis. Teknologi push notifikasi yang digunakan memanfaatkan firebase sebagai media penyampaian pesan berupa stock terkini ke pengguna. Sehingga pengguna akan selalu update mengenai stock barang yang dimilikinya.
\end{abstract}

Kata kunci: Android, Monitoring, Push Notification, Stock 


\section{PENDAHULUAN}

PT Mebel Kisaran merupakan perusahaan yang bergerak dalam pembuatan furniture rumah tangga seperti lemari, kuris, sofa, dan sebagainya. Agar produksi atau pembuatan barang-barang furniture dapat berjalan dengan baik tentunya barang mentah seperti kayu, besi, kawat, paku, dan lainnya yang merupakan barang bakunya harus selalu tersedia. Jika terjadi kekosongan barang baku tersebut tentunya akan berpengaruh terhadap kelangsungan proses produksi. Pembuatan furniture akan tertunda hingga barang bakunya tersedia kembali. Hal ini menjadi masalah tahunan yang dihadapi oleh perusahaan tersebut.

Setelah dilakukan penelitian diperoleh informasi bahwa hal tersebut terjadi karena lambatnya informasi yang diperoleh mengenai stok barang baku, karena pengelolaannya yang memang masih manual. Pemanfaatan teknologi tentunya menjadi solusi untuk mengatasi hal tersebut.

Pemanfaatan teknologi sudah menjadi hak yang biasa dilakukan oleh pelaku bisnis, baik produsen maupun distributor, mulai dari partai kecil hinga partai besar. Selain pengelolaan data barang nya yang berbasis teknologi, pemantauan stok juga dapat dilakukan dengan pemanfaatan teknologi. Salah satu teknologi yang sangat berkembang hingga saat ini adalah perkembangan teknologi mobile, seperti ponsel misalnya. Jika dulu penggunaan ponsel hanya untuk melakukan panggilan dan sms, sekarang sudah dapat digunakan untuk kebutuhan yang lebih luas lagi, apalagi sejak munculnya smartphone.
Pengguna smartphone di Indonesia mencapai 177,9 juta pengguna dengan tingkat penetrasi mencapai 67\% yang dihimpun oleh hootsuite.com januari 2018 [1]. Berdasarkan data tersebut memperlihatkan bahwa pengguna mobile semakin berkembang pesat, untuk itu pengembangan aplikasi yang berbasis android sangat diperlukan, terutama untuk monitoring stock barang, karena dapat diakses kapanpun dan dimanapun.

Untuk itu pimpinan melakukan investasi IT untuk pengembangan aplikasi yang mampu memantau stok barang dengan realtime, sehingga saat stok menipis dapat dilakukan antisipasi dengan cepat.

Aplikasi ini akan bekerja pada smartphone android yang nantinya akan terintegrasi dengan firebase console. Peran firebase dalam sistem ini adalah untuk mengirim informasi dalam bentuk push notification yang nantinya dari firebase akan dilanjutkan ke smartphone android pengguna yang telah melakukan pemasangan aplikasi ini [1].

\section{LANDASAN TEORI}

Dalam penelitian ini menggunakan android sebagai sebagai basis dari aplikasi yang dibuat. Android sendiri merupakan software untuk perangkat mobile yang mencakup sistem operasi, middleware, dan kunci aplikasi. Dimana terintegrasi dengan Android SDK (Software Development Kit) yang menyediakan tools dan API yang diperlukan untuk memulai mengembangkan aplikasi dengan menggunakan bahasa Java dan Kotlin [2].

Bahasa java sendiri menjadi bahasa awal dari pengembangan aplikasi android. 
Java sendiri menjadi bahasa pemrograman popular yang dikembangkan oleh Sun Microsystem, dimana bahasa pemrograman ini bersifat multiplatform yakni bahasa ini dapat digunakan di berbagai platform, seperti desktop, android dan bahkan untuk sistem operasi Linux [3].

Sementara Kotlin menjadi bahasa yang terbilang baru untuk pengembangan aplikasi android. Dimana basis dari Kotlin adalah Java Virtual Machine (JVM) yang dikembangkan oleh JetBrains. Kotlin sendiri merupakan bahasa pemrograman yang pragmatis untuk android yang mengkombinasikan object oriented (OO) dan pemrograman fungsional [3].

Pada aplikasi android yang dibuat nanti akan diintegrasikan dengan firebase agar dapat menerima pesan push notifikasi. Sebagaimana dalam penelitian sebelumnya dibahas bahwa Push Notification merupakan layanan teknologi yang digunakan untuk melakukan pemberitahuan melalui pesan pendek yang ada di smartphone. Dengan adanya layanan Push Notification tersebut, pengguna dapat terbantu dalam hal yang bersifat pemberitahuan secara singkat [4].

\section{METODE PENELITIAN}

Metodologi penelitian yang digunakan adalah kualitatif dimana peneliti mencoba memahami secara mendalam fenomena yang diteliti dalam setting yang alami. Karenanya pendekatan ini juga dapat dikategorikan sebagai pendekatan fenomenologi. Metode yang digunakan dalam pendekatan ini adalah studi kasus. Studi kasus pada penelitian ini dilakukan pada PT Mebel Kisaran.

Adapun langkah-langkah metode penelitian dalam penyelesaian penelitian ini dimulai dengan tahap perencanaan, pengumpulan data, analisis, tahap perancangan sistem Aplikasi Mobile Push Notifikasi Berbasis Android Untuk Monitoring Stock, dan diakhiri dengan tahap Implementasi.

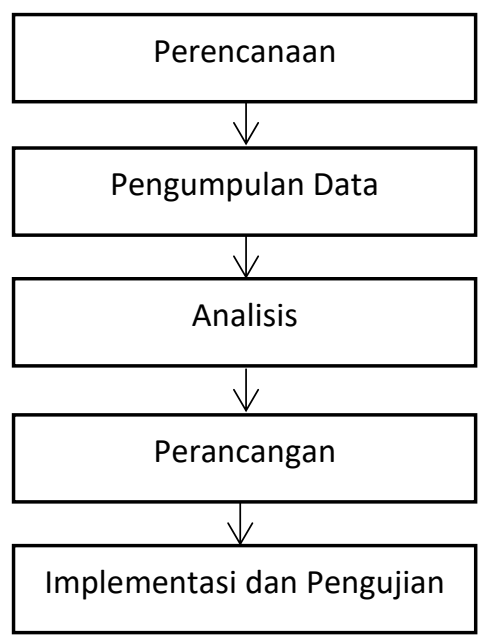

Gambar 1. Kerangka Kerja Penelitian

Pada tahap perencanaan dimulai dari melihat fenomena yang terjadi di PT Mebel Kisaran, dimana terjadinya kekosongan stock setiap tahunnya.

Tahapan pengumpulan data dilakukan dengan cara observasi dan wawancara terhadap pimpinan dan staf secara langsung. Tahap analisis dilakukan dengan menganalisis hasil dari data observasi dan wawancara yang telah dikumpulkan sebelumnya untuk mengetahui kebutuhan rancangan sistem yang akan dibangun. Berdasarkan data tersebut diperoleh informasi bahwa selama 1 tahun dapat terjadi 9 kali kekosongan stok. Selama stok barang baku tidak tersedia proses produksi akan dihentikan sekitar 2 hari kerja. Sehingga dapat diambil kesimpulan bahwa dalam 1 tahun terdapat 18 hari kerja yang kan terbuang sia-sia dan akan menurunkan produktivitas perusahaan. 
Tahap perancangan dilakukan dengan merancang sistem sesuai dengan kebutuhan yang telah dianalisa pada tahap analisisa, adapun proses pada aplikasi monitoring nanti akan ditunagkan dalam tahap implementasi. Sehingga di tahap terakhir yaitu tahap Implementasi dan pengujian ini dilakukan pembuatan aplikasi berdasarkan semua rancangan yamg dilakukan sehingga menjadi sebuah aplikasi utuh, kemudian dilakukan pengujian aplikasi dari hasil implementasi sistem monitoring stok barang tersebut.

\section{HASIL DAN PEMBAHASAN}

\section{Hasil}

Hasil dari penelitian ini adalah sebuah aplikasi monitoring stok barang berbasis android yang menggunakan teknologi push notification sebagai pesan informasi yang akan terkirim kepada pengguna. Untuk menjalankan sistem ini pengguna harus melakukan instalasi pada smartphone android masisng-masing pengguna dimana sistem ini akan menampilkan informasi yang berhubungan dengan stok barang baku (Gambar 2).

Jika stok barang sudah menipis terdapat informasi yang akan dikirimkan sebagai pesan notifikasi sehingga meskipun pengguna tidak membuka aplikasi tersebut dapat mengetahui informasi tersebut melalui pesan notifikasi yang dikirimkan, hal ini memungkinkan pengguna dengan cepat mengetahui stok barang yang sudah menipis.

\section{Pembahasan}

Monitoring stok barang yang dilakukan memanfaatkan layanan Firebase Cloud Massaging untuk mengirimkan pesan notification pada pengguna. Alur prosesnya dimulai saat salah satu stok barang yang ada dalam data sudah menipis seperti yang terlihat pada gambar 2. Stok kayu sudah menipis menyisakan 5 kubik, maka secara otomatis aplikasi akan mengirimkan pesan yang berisi peringatan stok menipis ke firebase, selanjutnya firebase yang akan melakukan push dengan meneruskan pesan ke perangkat pengguna.

Pengguna akan menerima pesan dalam bentuk notifikasi di smartphone androidnya, ditandai dengan icon notifikasi di pojok atas layar smartphone pengguna, seperti terlihat pada gambar 3.

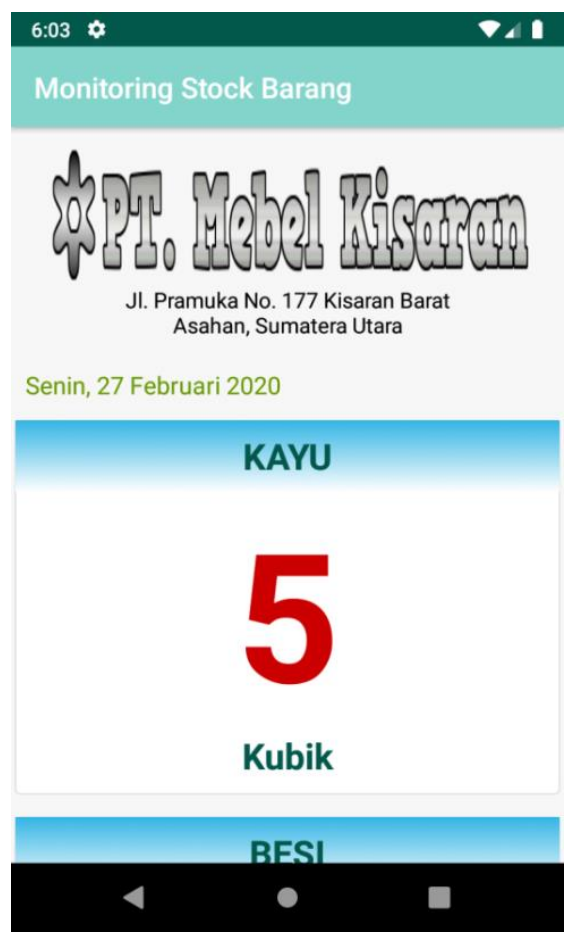

Gambar 2. Tampilan Awal Aplikasi 


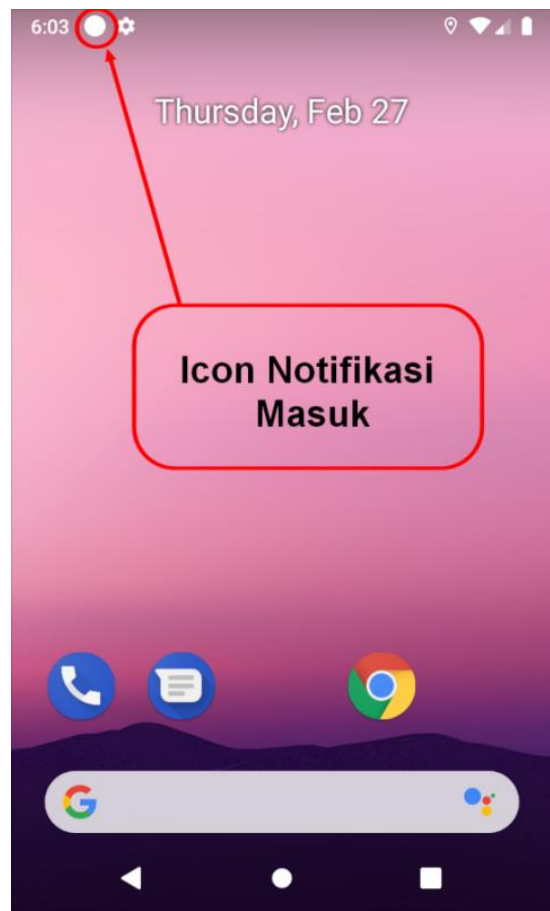

Gambar 3. Notifikasi Pesan Masuk

Selanjutnya swipe pada actionbar smartphone untuk melihat preview pesan notifikasi yang masuk (gambar 4), ketika preview pesan diklik maka aplikasi monitoring stok barang akan dijalankan sehingga halaman awal akan ditampilkan seperti pada gambar 2 sebelumnya.

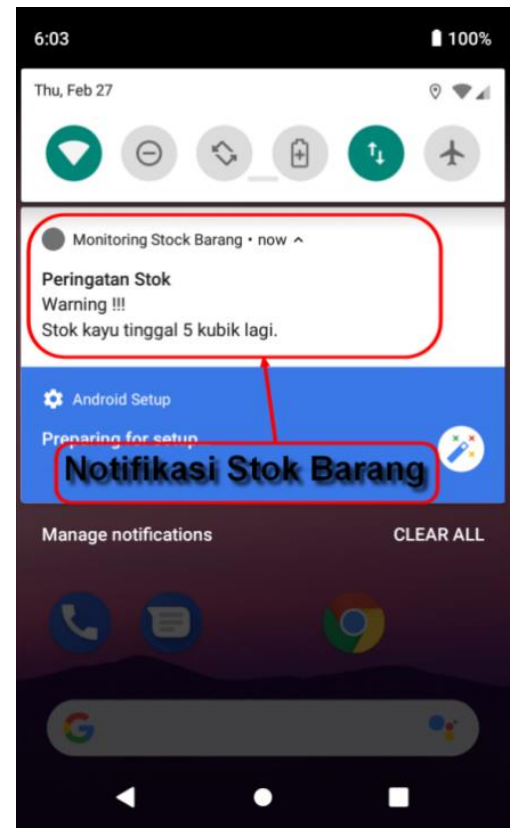

Gambar 4. Preview Pesan Notifikasi

Pesan peringatan stok dalam bentuk push notifikasi sebagaimana terlihat pada gambar 4 bertujuan untuk memantau atau memonitoring stok barang di PT Mebel Kisaran. Aplikasi akan memonitoring stok secara realtime sesuai dengan keadaan terkini.

\section{V.SIMPULAN DAN SARAN}

Pada penelitian ini, aplikasi dapat berjalan dan dapat digunakan untuk menggirimkan informasi stok barang kepada pengguna. Pengguna yang dimaksud disini adalah pengguna yang memiliki hak atau tanggung jawab dibidang tersebut, seperti pimpinan dan penjaga gudang.

Adapun informasi yang disampaikan dalam pesan notifikasi tersebut berupa stok 
barang tertentu yang memang sudah menipis. Sementara itu informasi stok yang tersedia di aplikasi dapat di kelola oleh operator atau pengguna lain yang memiliki peran untuk mengelola barang baku. Pengelolaan data stok yang baik akan berpengaruh terhadap aplikasi monitoring ini.

Penelitian ini juga masih dapat dikembangkan kedepannya dengan penambahan notifikasi web misalnya dan atau penambahan alarm pengingat. Selain itu perlu juga ditambahkan analisi forecast atau peramalan stok kedepannya agar pengelolaan stok terus meningkat dan produktivitas perusahaan akan terus meningkat.

\section{DAFTAR PUSTAKA}

[1] Siddik, M., \& Nasution, A. (2018, September). Teknologi Push Notifikasi Berbasis Android Untuk Informasi Perkuliahan (Studi Kasus: STMIK Royal Kisaran). In Seminar Nasional Royal (SENAR) (Vol. 1, No. 1, pp. 41-44).
[2] Mukaromah, H., \& Amelia, K. R. (2019). Perancangan Aplikasi Penjualan Tapis Lampung Berbasis Android Menggunakan Algoritma String Matching. Aisyah Journal Of Informatics and Electrical Engineering (AJIEE), 1(1), 30-38.

[3] Sibarani, N. S., Munawar, G., \& Wisnuadhi, B. (2018, October). Analisis Performa Aplikasi Android Pada Bahasa Pemrograman Java dan Kotlin. In Prosiding Industrial Research Workshop and National Seminar (Vol. 9, pp. 319-324).

[4] Nasution, A. (2018). Perancangan Aplikasi Push Notification Berbasis Android. JURTEKSI, 4(2), 149-154.

[6] Nasution, A. dkk (2019). Pelatihan Membuat Aplikasi Android Dengan Android Studio Pada SMP Negeri 1 Tinggi Raja. (Jurdimas) (Vol 2, No. 1, pp-53-58)

[7] Siregar, I.K., \& Efendi, B (2015, AGustus). Sistem Informasi Stok Obat Beserta Alert Dengan Visual BasiC 2008. In Seminar Nasional Informatika 2015. (Vol. 1, No. 1, pp. 690-693) 